\title{
The Sweet Escape: Effects of Mortality Salience on Consumption Quantities for High- and Low- Self-Esteem Consumers
}

\author{
NAOMI MANDEL \\ DIRK SMEESTERS*
}

\begin{abstract}
This research demonstrates that exposure to death-related stimuli can increase consumers' amounts of purchasing and consumption. We demonstrate that consumers who have been recently reminded of their own impending mortality wish to purchase higher quantities of food products (and actually eat higher quantities) than do their control counterparts. This effect occurs primarily among low-selfesteem consumers. We explain our findings in terms of escape from self-awareness. Low (but not high) self-esteem participants overconsume in response to a mortality salience activation as a means to escape from self-awareness. We also address alternative explanations for these effects.
\end{abstract}

$\mathrm{F}_{\mathrm{cos}}$ ear of death is inherently rooted in human nature. To counter this fear, humans have a basic predisposition to avoid threats to continued existence. Faith in one's culture and bolstering one's self-esteem can provide a protective shield against the anxiety that results from awareness of the inevitability of death. Current events such as terrorist attacks or natural disasters can dramatically increase the salience of death-related concerns (Pyszczynski, Solomon, and Greenberg 2003). For example, in the aftermath of the terrorist attacks on September 11, 2001, the media documented evidence of Americans' desire to "seize the day" by engaging in excessive consumption (Cosgrove 2001). This overconsumption took the form of buying expensive, luxury products (White and Leung 2002) as well as bargain shopping, stocking up on canned goods, and overconsuming sweets (Hubler 2001). This anecdotal evidence suggests that increased mortality salience (MS) may lead consumers to excessively consume as a way to cope with thoughts of impending mortality. To date, only a hand-

*Naomi Mandel is associate professor of marketing, and Dean's Council of 100 Distinguished Scholars, at the W. P. Carey School of Business, Arizona State University, P.O. Box 874106, Tempe, AZ 85287-4106 (naomi.mandel@asu.edu). Dirk Smeesters is associate professor of marketing at the Rotterdam School of Management, Erasmus University, P.O. Box 1738, 3000 DR Rotterdam, Netherlands (dsmeesters@ rsm.nl). Corresponding author: Naomi Mandel. The authors would like to thank Katherine Loveland, Amy Dalton, Lacey Wieser, and participants in a doctoral seminar at Tilburg University for their helpful comments.

John Deighton served as editor and Baba Shiv served as associate editor for this article.

Electronically published May 14, 2008 ful of empirical studies have addressed the effects of MS on consumer behavior (Kasser and Sheldon 2000). One example (Ferraro, Shiv, and Bettman 2005) focused on dietary choices from a given assortment of products, whereas our current research examines the quantity of products purchased and consumed (Chandon and Wansink 2006).

In a series of experiments, we test the effects of MS on the consumption quantity of food and drink products, both hypothetical (experiments 1,2, and 4) and actual (experiment 3), as well as the moderating role of consumers' selfesteem. We demonstrate that consumers who have been recently reminded of their own impending mortality wish to purchase higher quantities (and actually eat higher quantities) than do their control counterparts. This effect is more pronounced for low-self-esteem consumers than for highself-esteem consumers. We also examine various alternative explanations for our results. Using both mediation and moderation analyses, we demonstrate that low, but not high, selfesteem consumers overconsume in response to an MS activation as a means to escape from self-awareness.

\section{MORTALITY SALIENCE AND CONSUMPTION}

Since September 11, 2001, Americans have become increasingly aware of their own inevitable mortality (Spencer and Crossen 2003). Becker (1973) argued that people counter their fear of death by creating a cultural worldview, which gives meaning and order to the world. According to terror management theory (Greenberg, Pyszczynski, and Solomon 1986), this cultural worldview establishes an anx- 
iety buffer between the individual and the uncertain universe. Reminding people of their own mortality causes them to bolster their own cultural worldviews and makes them defensive toward threats to their worldviews. For example, Greenberg et al. (1990) showed that manipulating MS leads to stronger preferences among Americans toward those who praise the United States than among those who criticize it. Another way to counteract this fear of death is to maintain a high level of self-esteem, which may provide a buffer against the fear of death (Solomon, Greenberg and Pyszczynski 1991). Upon activation of MS, individuals increase behaviors that bolster their self-esteem. For example, Arndt, Schimel, and Goldenberg (2003) found that MS increases intentions to work out when fitness is viewed as an important source of self-esteem (Harmon-Jones et al. 1997).

Individuals can also cope with their existential concerns through their consumption behavior (Arndt et al. 2004). For example, Mandel and Heine (1999) found that consumers exposed to death-related information demonstrated increased interest in purchasing luxury brands (compared to nonluxury brands), which may reinforce a consumer's social status within a consumer-driven culture. Furthermore, Kasser and Sheldon (2000) found that MS participants, compared to control participants, projected higher salaries for themselves in the future, and they expected to spend more on pleasurable items such as clothing and entertainment. These prior studies support the notion that materialism might represent a dominant cultural worldview (Arndt et al. 2004). Materialism is defined as a belief that the acquisition of material possessions (which are often status-laden) will make one happy (Richins and Dawson 1992). While related to materialism, we instead choose to study the purchase and consumption incidence (Chandon and Wansink 2006) of consumable household products such as food and drinks, which are unlikely to be accumulated in large quantities as a means of signaling status.

Other research has suggested that MS can affect consumers' choices via self-esteem striving. Ferraro et al. (2005) found that, after exposure to an MS prime, female consumers were more likely to choose to eat chocolate cake (compared to a fruit salad), but only when they were low on body esteem. The authors argued that females with higher body esteem preferred the fruit salad as a means to bolster selfesteem as a defense against mortality anxiety. Rather than focusing on a choice between two food items such as cake and fruit salad, our research focuses on how MS affects the quantity of consumption. We demonstrate that MS individuals, both male and female, want to consume higher quantities of both hedonic and utilitarian products (i.e., the cake and the fruit salad). Our findings suggest that MS consumers who are low in self-esteem engage in increased consumption because they wish to escape from self-awareness rather than to bolster self-esteem. By focusing on the immediate sensations resulting from disinhibited consumption (Heatherton and Baumeister 1991), they are able to avoid confronting their existential anxieties.

\section{OVERCONSUMPTION AS ESCAPE FROM SELF-AWARENESS}

According to objective self-awareness theory (Duval and Wicklund 1972), awareness of the self is an aversive state in which the self is compared, often unfavorably, to accessible standards. Self-awareness increases when individuals are reminded of themselves, for example, when facing a mirror (Duval and Wicklund 1972). When self-awareness is high, discrepancies between the actual self and the ideal self (or societal and cultural standards) become more salient. Individuals in a high state of self-awareness tend to try to reduce such discrepancies. For example, self-aware individuals are more accurate in their reports of their own personality traits (Pryor et al. 1977) and emotions (Scheier and Carver 1977) and less likely to exhibit aggression against others (Scheier, Fenigstein, and Buss 1974) than individuals who are not self-aware. In other words, people in a state of high self-awareness are less likely to deceive themselves or others about their own character traits and attitudes and thus may feel the need to change their behavior in order to better conform to ideal standards.

Individuals who feel unable to meet ideal standards may try to escape this aversive state of self-awareness by turning their attention away from themselves. Attempts to escape self-awareness may result in extremely self-destructive behaviors such as alcohol abuse, suicide (Baumeister 1990), or binge eating (Heatherton and Baumeister 1991). Alternatively, individuals may engage in less-destructive behaviors in order to avoid self-focus, such as television viewing (Moskalenko and Heine 2003) or disinhibited eating of foods such as chocolate or cookies (Polivy, Herman, and McFarlane 1994).

An individual's self-esteem may be threatened by thoughts of mortality if the individual fears dying without leaving a significant mark on the universe. Two well-established strategies to try to counteract or buffer such fears are (1) bolstering one's self-esteem and (2) defending one's cultural worldview (Greenberg et al. 1986). We examine a third strategy, escape from self-awareness, as an alternative means to counteract a mortality threat. Prior research has demonstrated a link between MS and high levels of selfawareness. For example, Silvia (2001) showed that selfawareness can increase thoughts of mortality. Conversely, thoughts of mortality might also increase self-awareness. Alternatively, MS might make self-awareness particularly aversive. Highly self-aware individuals may feel that alternative strategies for buffering MS, such as self-esteem bolstering and worldview defense, are not viable for them, since such strategies require a certain level of self-delusion. For example, Arndt et al. (1998) found that MS participants spent less time in cubicles containing a mirror (study 1) and spent less time writing stories about their internal thoughts (study 2) than did control participants.

By extension, we expect that awareness of death will lead consumers to demonstrate higher levels of consumption of such products as food and drinks, because one way to avoid 
anxiety-laden reminders of self-awareness is via disinhibited consumption. While engaging in disinhibited eating, individuals are able to narrow their attention to the immediate sensations resulting from eating and drinking, thereby avoiding existential thoughts (Heatherton and Baumeister 1991). Consistent with this reasoning, ego threats (Heatherton, Herman, and Polivy 1992) and self-esteem threats (Polivy et al. 1994) have been shown to increase the amount of eating among restrained eaters. Therefore, engaging in consumption may be one way for individuals to counteract the threat of death. Hence, we propose that MS will lead to excessive consumption. We also expect self-esteem to moderate these proposed effects, as described in the next section.

\section{SELF-ESTEEM AND OVERCONSUMPTION}

Excessive consumption, as a means of escape from selfawareness, might take the form of either overeating or excessive shopping (or both). Compulsive spenders demonstrate lower self-esteem than other consumers (Faber and O'Guinn 1992), and they often employ spending as a means to enhance self-esteem (Hanley and Wilhelm 1992). Similarly, there is a high correlation between binge eating and low self-esteem (French, Story, and Perry 1995). Therefore, although not central to our theory, we expect individuals with low self-esteem to exhibit higher consumption levels than those with high self-esteem. More importantly, we expect self-esteem to moderate the effect of MS on consumption levels.

Ferraro et al. (2005) found that MS caused only highbody-esteem consumers to choose fruit salad over cake, since their bodies were viewed as an important source of self-esteem. By choosing a fruit salad, they could avoid gaining weight and continue to use their bodies as a source of self-esteem. However, the question remains of what Ferraro et al.'s (2005) low-body-esteem participants, who demonstrated the strongest effects, were doing while the highbody-esteem consumers were bolstering their self-esteem. Individuals low in body or self-esteem are unlikely to bolster their esteem by eating additional calories. Instead, by choosing the cake, we believe that they are following an escape strategy (Heatherton and Baumeister 1991) rather than a self-esteem-striving strategy, to avoid existential threat.

Individuals are frequently motivated to maintain high levels of self-esteem, in part because it protects them from the potential anxiety resulting from MS (Pyszczynski et al. 2004). When self-esteem is high, individuals experience a relatively low level of death-related anxiety and thus may not need to use any coping strategies or defenses in the face of MS. Highself-esteem (HSE) individuals may even implicitly engage in self-affirmation as a way to enhance self-integrity and protect oneself against such ego threats (Schmeichel and Martens 2005). However, low-self-esteem (LSE) individuals experience a relatively high level of death-related anxiety, which causes them to engage in defensive behavior or self-enhancing strategies in order to counter their fears of death (Pyszczynski et al. 2004).

When LSE individuals are given the opportunity to bolster their self-esteem (e.g., by giving higher ratings to political, cultural, or religious in-groups vs. out-groups), they will do so, presumably in an attempt to cope with existential anxiety (Harmon-Jones et al. 1997). However, when faced with the decision of how much to consume (e.g., of snacks and drinks), their viable options are unlikely to be effective in bolstering self-esteem. While HSE individuals have the selfesteem resources to face a mortality threat head-on (i.e., without changing consumption strategies), LSE individuals are unlikely to feel bolstered by keeping consumption levels constant. Furthermore, they are unlikely to feel bolstered by decreasing their consumption of food (since they tend not to view their bodies as meeting cultural standards; Ferraro et al. 2005). Finally, they are unlikely to feel bolstered by increasing consumption levels, since this behavior will only increase the distance between their own bodies and ideal standards. Therefore, LSE individuals have no other choice but to follow a different strategy: escape from self-awareness. Following an escape from self-awareness strategy should disinhibit consumption (Heatherton and Baumeister 1991), thereby increasing consumption quantities.

H1: Self-esteem will moderate the effect of MS on the consumption quantity of food and drinks. The positive effect of MS on consumption quantity will be stronger for LSE consumers than for HSE consumers.

We present a pilot study and four experiments that examine MS effects on consumption patterns. In experiment 1 , we test hypothesis 1 , which predicts an effect of MS on consumption quantities of food and drinks that should be stronger for LSE consumers than for HSE consumers. In experiments $2-3$, we examine the extent to which escape from self-awareness mediates the effect of MS on consumption quantities. Finally, in experiment 4, we heighten the level of self-awareness and examine whether it moderates the influences of MS and self-esteem on consumption. In summary, we provide evidence that consumers try to defend themselves against the potential anxiety induced by thoughts of death by increasing the quantity of consumption as a means to escape from self-awareness.

\section{PILOT STUDY}

An initial pilot study investigated whether MS affected the quantity of food and drink items that individuals wished to purchase, regardless of self-esteem levels. Participants, 32 students enrolled in a summer marketing course, were randomly assigned to either the MS condition or the control condition. The MS participants completed an essay that addressed the following: (1) please briefly describe the emotions that the thought of your own death arouses in you, and (2) jot down, as specifically as you can, what you think will happen to you as you physically die and once you are physically dead. The control participants were given the following: (1) please briefly describe the emotions that the thought of visiting the dentist arouses in you, and (2) jot 
down, as specifically as you can, what you think will happen to you the next time you have a painful procedure done at the dentist's office (Rosenblatt et al. 1989). Then they completed the Positive and Negative Affect Schedule (PANAS), which measures affect (Watson, Clark, and Tellegen 1988), and were asked several filler questions. The purpose of these filler tasks was to allow time for activation to spread while removing thoughts of death from immediate consciousness (Greenberg et al. 1994). Finally, they circled all of the items from a prepared grocery list that they intended to buy in the next week, including fresh fruits, fresh vegetables, fresh meat, canned items, snacks, canned meat, beverages, and frozen food.

MS participants selected significantly more total items $(M=30.64$ vs. $23.28 ; F(1,30)=7.47, p<.01)$ than did control participants, including significantly more fresh vegetables $(M=5.50$ vs. $3.67 ; F(1,30)=9.99, p<.005)$, fresh meats $(M=4.50$ vs. $3.33 ; F(1,30)=4.15, p<.05)$, canned meats $(M=1.86$ vs. $1.22 ; F(1,30)=3.84, p=$ $.05)$, and frozen foods $(M=2.07$ vs. $1.44 ; F(1,30)=$ $6.04, p<.05)$. Consistent with numerous findings in the terror management literature (Greenberg, Solomon, and Pyszczynski 1997), participants' levels of positive and negative affect, as measured by the PANAS, did not differ significantly as a result of the manipulation. Therefore, our findings cannot be explained as the result of positive or negative affect ensuing from the manipulations. The PANAS measures of positive and negative affect also were not influenced by the independent variables and did not influence our dependent variables in any of the subsequent studies and thus are not subsequently reported.

These results provide preliminary support for the idea that MS individuals want to consume a larger quantity of products than do others. Furthermore, these findings are inconsistent with an explanation that our participants simply wish to "eat, drink [and be merry]" (Ferraro et al. 2005). An increased desire to purchase not only snacks and drinks, but also fresh and frozen vegetables, as well as fresh and canned meats, seems to imply that participants are stocking up for reasons other than pure hedonic pleasure.

\section{EXPERIMENT 1}

The goal of experiment 1 was to test hypothesis 1 , which suggests that self-esteem may moderate the effects of MS on planned purchases of food and drinks. We also varied the given budget from $\$ 75$ to $\$ 150$, reasoning that participants might blow their budgets more when they were given smaller budgets. Thus, we used a 2 (MS: death vs. dentist) $\times 2$ (self-esteem: low vs. high) $\times 2$ (budget: $\$ 75$ vs. $\$ 150)$ between-subjects design.

\section{Method}

In exchange for partial course credit, 392 marketing students completed the questionnaire. As in the pilot study, participants were randomly assigned to either the MS condition, which included an essay about what would happen when they die, or the control condition, which included an essay about what would happen when they went to the dentist. They next completed the PANAS and filler questions. We then told them to imagine that they were hosting an informal party for friends and to circle the items on a hypothetical shopping list of items they might buy for a party. They were allowed a budget of either $\$ 75$ or $\$ 150$. The list contained 79 possible items, including the following categories: snacks (23), dips (10), cookies (12), crackers (7), beer (9), liquor (9), nonalcoholic beverages (5), and miscellaneous items such as balloons and cake (4). Each product was listed on a separate line, with the brand, size, and price of the product. There was also a blank page to allow participants to add any other items they wished to buy. We measured self-esteem using the Rosenberg self-esteem scale at the end of the questionnaire (Rosenberg 1989).

\section{Results}

We performed a 2 (MS: death vs. dentist) $\times 2$ (selfesteem: low vs. high; median-split) $\times 2$ (budget: $\$ 75$ vs. $\$ 150)$ between-subjects ANOVA. The analysis of variance revealed a main effect of the MS manipulation on the total number of items chosen. MS participants selected more items from the grocery list $(M=25.64$ vs. 22.73; $F(1,384)=6.62, p<.01)$, spent more total dollars $(M=$ $\$ 139.85$ vs. $\$ 125.02 ; F(1,384)=6.10, p<.01)$, and spent a higher percentage of their budgets $(M=131 \%$ vs. $113 \%$; $F(1,384)=7.38, p<.01)$ than did control participants. Not surprisingly, there was also a main effect of budget, with individuals who were given a higher budget choosing more items $(F(1,384)=52.01, p<.0001)$ and spending more money $(F(1,384)=72.37, p<.0001)$ than those who had a lower budget. The amount of the budget did not interact with the MS manipulation.

There was also a main effect of self-esteem on the number of items chosen $\left(M_{\mathrm{LSE}}=26.01\right.$ vs. $M_{\mathrm{HSE}}=22.82$; $F(1,384)=3.96, p<.05)$. Furthermore, the MS $\times$ selfesteem interaction reached significance $(F(1,384)=4.25$, $p<.05)$. As predicted in hypothesis 1 , the MS effect emerged as significant for LSE consumers $(F(1,384)=$ $8.19, p<.005)$ but not for HSE consumers $(F(1,384)=$ $0.17, p>.50)$. LSE consumers chose more items from the grocery list in the MS condition $(M=29.06)$ compared to the control condition $(M=23.37)$. For HSE consumers, there was no significant difference between the MS and the control condition ( $M=23.39$ vs. 22.21). Figure 1 illustrates these results.

\section{Discussion}

The results of experiment 1 demonstrate that MS leads to increased food and drink consumption, particularly for consumers with low self-esteem. In the next section, we further discuss our proposed mechanism (escape from selfawareness) and distinguish it from another potential explanation of our results (self-regulatory failure), which we argue is unlikely to account for our results. We then present 
FIGURE 1

EXPERIMENT 1 RESULTS: THE EFFECTS OF MORTALITY SALIENCE AND SELF-ESTEEM ON TOTAL ITEMS SELECTED

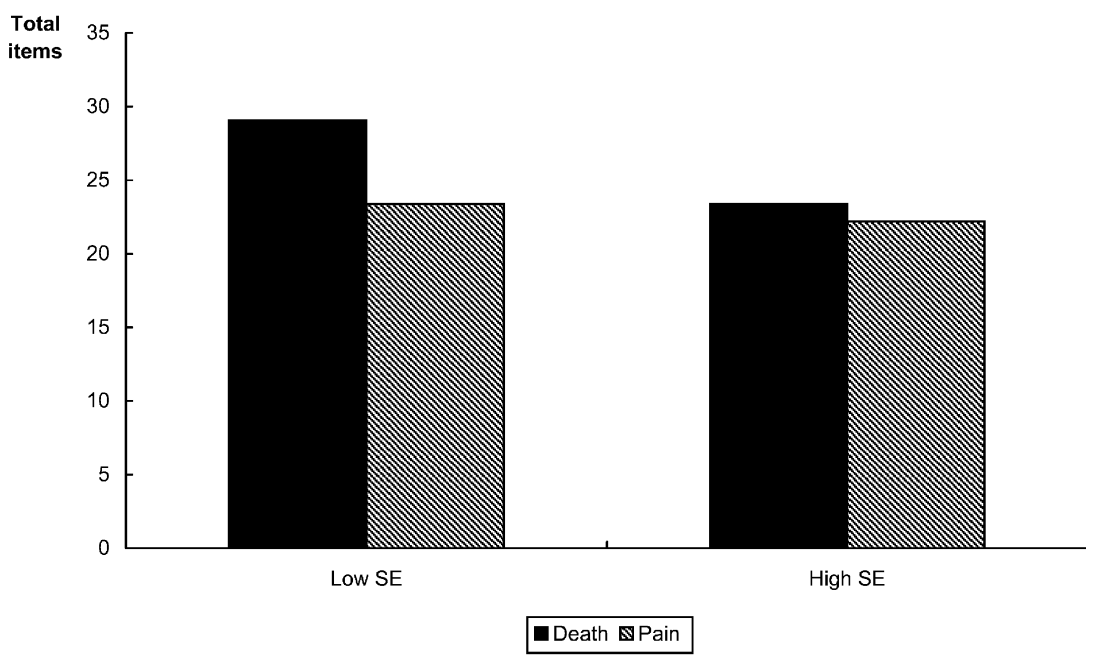

three experiments in which we provided empirical evidence for the role of escape from self-awareness in explaining MS effects on consumption behavior.

\section{EXAMINING THE PROCESS: ESCAPE FROM SELF-AWARENESS OR SELF- REGULATORY FAILURE?}

Our proposed theoretical model suggests that escape from self-awareness is the explanatory process for the effects of MS on overconsumption. However, self-regulatory failure (Baumeister, Heatherton, and Tice 1993) might provide an alternative explanation for our expected findings. For example, Gailliot et al. (2006) recently found that MS participants exhibited diminished performance on measures of self-regulation such as a Stroop task, a logical reasoning task, and a puzzle-solving task. Therefore, it is possible that our participants might demonstrate a lower level of selfcontrol due to $\mathrm{MS}$, thereby wishing to consume a higher quantity of food or other products. For example, egodepleted consumers have been shown to demonstrate higher levels of impulsive spending (Vohs and Faber 2007). However, we believe that escape from self-awareness provides a superior explanation for the MS $\times$ self-esteem interaction that we have found. In fact, Gailliot et al. (2006) measured self-esteem in several studies but found that it did not moderate the effects of MS on any of their dependent variables.

Furthermore, other prior research has established that high self-esteem can have a negative effect on self-regulation. For example, under conditions of ego threat, HSE individuals may set higher goals for themselves, thereby setting themselves up for failure (Baumeister et al. 1993). In fact, when faced with MS, HSE individuals (but not LSE individuals) increase the number of risky decisions they make, despite substantially increasing their risk for failure (Landau and Greenberg 2006). When people strive for high selfesteem, they are motivated to view themselves positively and therefore may have difficulty self-regulating because they fail to correctly appraise their current state relative to an ideal state (Crocker and Park 2004). In other words, HSE individuals might feel immune to the negative effects of either overeating (telling themselves "I can stand to gain a few pounds") or overbuying (telling themselves "I can afford to buy what I want"). Therefore, if our results can be explained in terms of differences in self-regulation, we might expect HSE individuals to be more susceptible to the effects of MS than are LSE individuals. On the contrary, our findings thus far have demonstrated stronger effects of MS for LSE individuals than for HSE individuals. Furthermore, if we can measure participants' desire to escape from selfawareness (e.g., via a choice to sit in front of a mirror or away from a mirror or via the use of first-person pronouns; Arndt et al. 1998; Dixon and Baumeister 1991) and establish this measure as a mediator between MS and consumption, we can strengthen the case for escape from self-awareness as the explanation for our effects. Since only LSE consumers change their consumption quantities as a result of MS, we expect mediation to occur only for LSE consumers.

H2: For low-self-esteem consumers, escape from self-awareness will mediate the relationship between MS and consumption quantity.

If MS makes self-awareness feel more aversive, what will happen if we further magnify LSE participants' level of selfawareness? The prior literature suggests two possibilities. On one hand, Arndt et al. (1998) found that MS participants spent less time in front of a mirror than did control participants, due to a wish to escape self-awareness. Therefore, 
it is possible that our MS participants who are forced to sit in front of a mirror will exhibit a stronger wish to escape self-awareness, leading to a higher consumption level compared to MS participants who are not placed in front of a mirror. On the other hand, Goldenberg et al. (2005) demonstrated that MS caused high-body-mass-index women to restrict their eating, particularly in situations where social comparison (and thus objective self-awareness) was likely. Therefore, it is also possible that the combination of MS and a mirror might reduce consumption levels. We propose that individuals must have the opportunity to escape from self-awareness in order for disinhibited consumption to occur. In other words, if MS participants are forced to face a mirror during both the manipulation and the consumption decision, they will be forced to confront the discrepancies between themselves and cultural standards (Duval and Wicklund 1972). If they feel they do not meet current standards of fitness or attractiveness, they might exhibit decreased food consumption (relative to a no-mirror condition), consistent with Goldenberg et al. (2005). However, if they face a mirror during the manipulation and then are allowed to move away from the mirror during the consumption decision, they will exhibit increased consumption (relative to a no-mirror condition) as a method to escape from self-awareness. Consistent with prior hypotheses, we expect these effects to occur primarily for LSE consumers.

H3: There will be a three-way interaction among MS, self-esteem, and manipulated self-awareness. Among LSE participants who receive an MS prime, those who are exposed to a mirror and allowed to escape will consume more than those who are not exposed to a mirror, who will consume more than those who are exposed to a mirror and not allowed to escape.

\section{EXPERIMENT 2}

In this experiment, we sought evidence for an escape from self-awareness process explanation for our findings in experiment 1 . We attempted to replicate the MS $\times$ self-esteem interaction and to demonstrate that escape from self-awareness mediates this effect.

In addition, we altered the control manipulation in this experiment in order to control for an unintended alternative explanation for our prior results: that people simply do not like to think about eating immediately after going to the dentist. Therefore, we changed the dentist manipulation to a pain manipulation, which required participants to address the following: (1) please briefly describe the emotions that the thought of having a painful medical procedure arouses in you, and (2) jot down, as specifically as you can, what you think will happen to you the next time you have a painful procedure done at your doctor's office. This control manipulation was designed to produce some mildly negative feelings without producing any death-related thoughts or caus- ing the participants to lose interest in eating (Arndt et al. 2003).

Before taking the dependent measure (choice of snacks and drinks from a shopping list), we measured whether participants wanted to escape from self-awareness. Specifically, participants had to choose a place to sit for a later task and could choose between two chairs: a chair facing a mirror or a chair facing away from a mirror (Greenberg and Musham 1981). Choosing to sit in front of a mirror is a reflection of embracing self-awareness, whereas choosing to sit away from a mirror is a reflection of escaping a state of self-awareness (Twenge, Catanese, and Baumeister 2003). Among LSE participants, we expected those exposed to a mortality prime to be more likely than those exposed to a control prime to attempt to escape from self-awareness by choosing the chair facing away from a mirror. In addition, we expected the choice to sit facing away from a mirror to mediate the effect of MS on the purchase quantities for LSE consumers.

\section{Method}

This experiment utilized a 2 (MS: death vs. pain) $\times 2$ (self-esteem: low vs. high) between-subjects design. Seventy participants came to the lab in partial fulfillment of course requirements. Participants sat in individual cubicles and completed questionnaire items in the following order: the Rosenberg (1989) self-esteem scale, several filler questionnaires, the death or pain essay (the manipulation), the PANAS, and several additional filler items.

Each participant was then led to a separate room in the same laboratory, containing two chairs with small desks. One chair was facing a full-size mirror against the wall, and the other chair was facing a blank wall. The experimenter told the participant that she or he had to perform the next task back inside the cubicle (which was in fact the dependent variable, i.e., picking snacks and drinks from a shopping list) and, after that, to fill out a final set of questions (which was in fact a postexperimental questionnaire) outside the cubicle (in these chairs, either facing the mirror or facing the wall), because the experimenter needed to prepare the cubicles for the next participant. The participant chose where to sit (facing the mirror or facing the wall) to fill out the final set of questions. The experimenter then placed the postexperimental questionnaire and a pencil on the desk of the chosen chair.

Each participant then went back to the original cubicle to complete the key dependent measure: hypothetical snack and drink choices for seven consecutive days. They were told that the products would be purchased from a vending machine and that the vendor would need to take all of their orders in advance (Kahn and Isen 1993). They were allowed to choose as many snacks and soft drinks as they desired from a variety of brands. Then, participants went to the other room, where they filled out a postexperimental questionnaire (on their chosen chair) that tested for their suspicion of any relatedness between the different phases of the experiment. None of the participants raised any such suspicion. 
FIGURE 2

EXPERIMENT 2 RESULTS: EFFECTS OF MORTALITY SALIENCE AND SELF-ESTEEM ON (A) THE CHOICE TO SIT AWAY FROM THE MIRROR AND (B) TOTAL ITEMS SELECTED

(A) Choice to sit away from the mirror

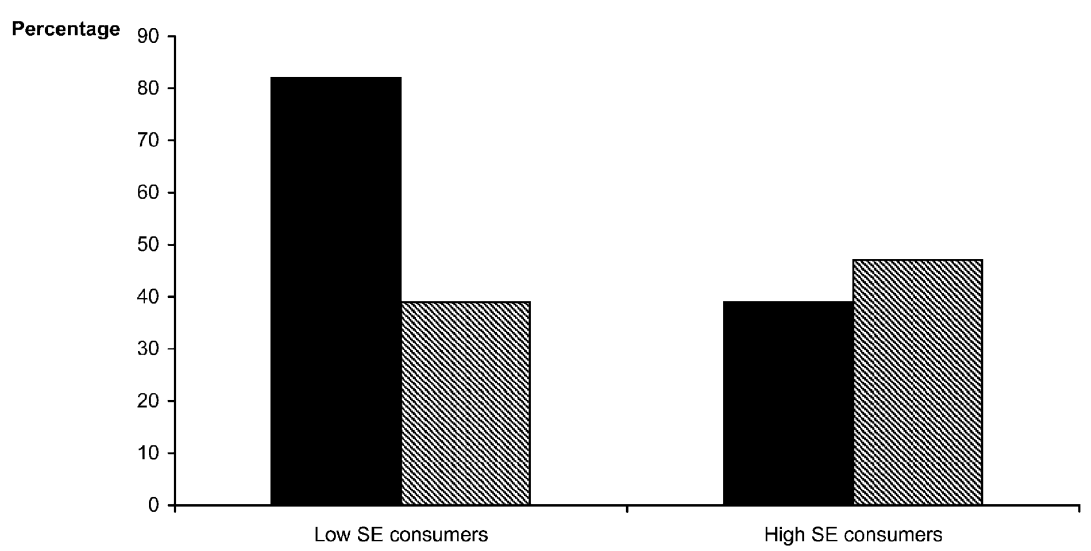

(B) Total items selected

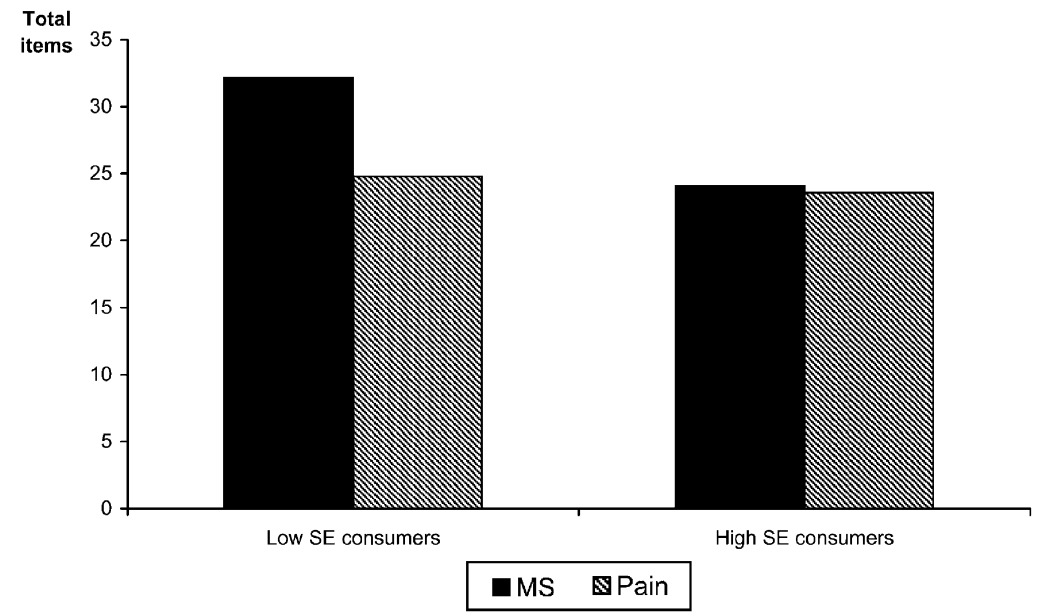

\section{Results}

Escape from Self-Awareness. There was no significant main effect of MS or self-esteem on the participants' choice to sit away from the mirror (both $\chi^{2}(70)=2.06$, NS). However, MS and self-esteem interacted in influencing the choice to sit away from the mirror $\left(\chi^{2}(70)=3.83, p=.05\right)$, as depicted in figure 2. More specifically, LSE participants who wrote about death chose more frequently to sit away from the mirror than did LSE participants who wrote about pain $(82 \%$ vs. $\left.39 \% ; \chi^{2}(70)=6.88, p=.01\right)$. However, HSE participants did not differ in their choice to sit away from the mirror $\left(39 \%\right.$ vs. $47 \% ; \chi^{2}(70)=0.24$, NS) as a result of the MS manipulation.

Purchase Quantities. We performed a 2 (MS: death vs. pain) $\times 2$ (self-esteem: low vs. high) between-subjects ANOVA on the total number of items chosen. The ANOVA revealed a main effect of $\operatorname{MS}(F(1,66)=6.06, p<.05)$. Participants who completed the death essay chose more items $(M=27.97)$ than did participants who completed the pain essay $(M=24.20)$. In addition, LSE participants chose more items $(M=28.34)$ than did HSE participants $(M=23.83$; $F(1,66)=8.51, p<.01)$. However, both main effects were qualified by an MS $\times$ self-esteem interaction $(F(1,66)=$ 4.70, $p<.05$; see fig. 2). As in experiment 1 , the MS effect was only significant for LSE participants $(F(1,66)=10.71$, $p<.01)$ but not for HSE participants $(F(1,66)<1, p>.83)$. LSE participants chose more items from the grocery list in the MS condition $(M=32.12)$ compared to the pain condition $(M=24.78)$. For HSE participants, there was no significant difference between the MS and the pain condition $(M=$ 24.06 vs. 23.59). We also ran separate analyses on the total number of snacks and drinks, and these analyses yielded results similar to the analysis on the total number of items chosen. 
Mediation Analyses. Our theoretical framework proposed a case of mediated moderation (Muller, Judd, and Yzerbyt 2005), where self-esteem moderates the effect of MS on the mediator, escape from self-awareness, which in turn influences consumption behavior. We tested mediated moderation with three models (Muller et al. 2005). The first model examines the effects of MS, self-esteem, and the MS $\times$ self-esteem interaction on the dependent variable (the total number of items chosen). This model confirmed the earlier reported interaction between MS and self-esteem on the total number of items chosen $(\beta=0.24, t=2.17$, $p<.05)$. The second model examined the effects of MS, self-esteem, and the MS $\times$ self-esteem interaction on the mediator (choice to sit away from the mirror) and confirmed the MS $\times$ self-esteem interaction on the mediator $(\beta=$ $0.26, t=2.25, p<.05)$. The third model added the mediator (choice to sit away from the mirror), and the interaction between self-esteem and the mediator, to the original model. In this model, the MS $\times$ self-esteem interaction was no longer significant $(\beta=0.07, t=0.69, p>.48)$, but the choice to sit away from the mirror had a significant effect on the number of items chosen $(\beta=0.40, t=3.95, p<$ .01). A Sobel (1982) test revealed that the decrease in the direct effect of the interaction effect of MS and self-esteem was statistically significant $(z=1.98, p=.05)$. Thus, the choice to sit away from the mirror is supported as a mediator of the effect of MS and self-esteem on the total number of items chosen.

\section{Discussion}

Experiment 2 provides further support that self-esteem moderates the effect of MS on consumers' choices for snacks and drinks. In addition, the results of this experiment support hypothesis 2, which proposed that, for LSE consumers, escape from self-awareness would mediate the relationship between MS and consumption quantity. Indeed, we found that LSE but not HSE participants wanted to escape from self-awareness when faced with a mortality threat. More LSE participants chose a chair that was facing away from a mirror after an MS prime than after a pain prime. This finding strongly supports our proposition that LSE consumers are in a state of escape from self-awareness when threatened by an MS activation. In contrast, HSE participants did not differ in their chair choice as a function of the prime. They did not attempt to escape from self-awareness, presumably because they have sufficient ego resources to counter this threat.

\section{EXPERIMENT 3}

In experiment 3 , we attempted to replicate our basic finding (the interaction between MS and self-esteem on consumption) and the mediational pattern in experiment 2 while using a different dependent variable (cookie eating) and a different measure of escape from self-awareness (a pronounusage task). Escape from self-awareness theory suggests that people often try to escape by focusing on immediate sen- sations such as eating food (Heatherton and Baumeister 1991), which may lead to overconsumption. Although the findings of our previous experiments support our proposition that LSE individuals overconsume because they want to escape self-awareness, one could still argue that selecting hypothetical items from a list seems quite different from consuming food. Heatherton and Baumeister (1991) argue that individuals can escape self-awareness by consuming food because they are able to focus on ongoing physical sensations, which might not be true when simply checking items off a shopping list. Therefore, to generalize our effects, we measure participants' actual rather than hypothetical eating behavior in experiment 3 by using a cookie-tasting paradigm (adapted from Mills et al. 2002).

\section{Method}

One hundred and three undergraduates participated as partial fulfillment of course requirements. As in prior experiments, this experiment had a 2 (MS: death vs. pain) $\times 2$ (self-esteem: low vs. high) between-subjects design. Participants came to the lab, sat in individual cubicles, and were told that they would participate in a series of unrelated tasks. They first filled out a series of questionnaires, including the Rosenberg self-esteem scale. Then, participants were randomly assigned to either the death essay or pain essay condition. Subsequently, they filled out the PANAS and several filler questions.

Next, participants completed a foreign language task, in which they examined a short story in a foreign language (Cyrillic Russian); 50 pronouns were underlined, and they had to guess the correct translation of each of the 50 pronouns. Our main interest was the number of first-person pronouns (I, me, my, myself, mine) that participants used in their translations. The use of first-person pronouns reflects one's level of self-awareness (Davis and Brock 1978), and using fewer first-person pronouns than usual reflects a desire to escape from self-awareness (Arndt et al. 1998).

After completing the translation task, participants were brought individually to an adjacent room where three plates were piled with three different flavors of small, freshly baked cookies. Each plate contained 15 cookies. The experimenter told each participant that a company wanted to test a new brand of cookie dough before it came on the market and that they would like to know which flavor tasted the best. Participants had to take one cookie per plate, taste it, and rate the cookie. They received a rating form per plate, on which they could rate the cookie on several dimensions. To make the cover story even more believable, participants were also asked to drink a little water between tasting each cookie. Participants were told that after all ratings were completed that they could help themselves to as many cookies as they wanted because the lab received more than enough cookies from the company. After the participants left the room, the experimenter counted the number of cookies that participants ate.

Finally, participants filled out a postexperimental questionnaire. None of the participants raised any suspicion 
about any of the manipulations or any relatedness between the different phases of the experiment. In addition, none of the participants was familiar with Russian.

\section{Results}

Escape from Self-Awareness. We counted the number of first-person pronouns each participant used to translate the foreign text. We then conducted a 2 (MS: death vs. pain) $\times 2$ (self-esteem: low vs. high) between-subjects ANOVA on the total number of first-person pronouns. There was a significant main effect of MS $(F(1,99)=4.23, p<.05)$; MS participants used fewer first-person pronouns $(M=$ $26.52)$ than did control participants $(M=28.86)$. There was also a main effect of self-esteem $(F(1,99)=6.23, p<$ $.05)$; LSE participants used fewer first-person pronouns $(M=26.27)$ than did HSE participants $(M=29.12)$. However, both independent variables interacted significantly with each other $(F(1,99)=8.10, p<.01)$. The effect of MS was only significant for LSE participants $(F(1,99)=12.14$, $p<.001)$ but not for HSE participants $(F(1,99)=0.31$, $p>.50)$. LSE participants in the MS condition used fewer first-person pronouns $(M=23.48)$ compared to those in the pain condition ( $M=29.06)$. HSE participants' use of firstperson pronouns did not differ between the two conditions $(M=29.56$ vs. 28.66).

Cookie Intake. We also performed a 2 (MS: death vs. pain) $\times 2$ (self-esteem: low vs. high) between-subjects ANOVA on the total number of cookies eaten. The ANOVA revealed a main effect of $\mathrm{MS}(F(1,99)=5.53, p<.05)$. Participants in the MS condition ate more cookies $(M=5.17)$ than did participants in the pain condition $(M=4.39)$. There was also a main effect of self-esteem $(F(1,99)=7.28, p<$ $.01)$. LSE participants ate more cookies $(M=5.23)$ than did HSE consumers $(M=4.33)$. Both main effects were qualified by the MS $\times$ self-esteem interaction $(F(1,99)=4.15$, $p<.05)$. The MS effect was significant for LSE consumers $(F(1,99)=9.73, p<.01)$. LSE consumers ate more cookies in the MS condition ( $M=5.96)$ compared to the pain condition $(M=4.50)$. For HSE consumers, there was no significant difference between the MS and the pain condition $(M=4.38$ vs. $4.28 ; F(1,99)=0.05, p>.50)$.

Mediation Analysis. As in experiment 2, we examined whether self-esteem moderates the effect of MS on our mediator, escape from self-awareness, which in turn should influence eating behavior, by following a mediated moderation approach (Muller et al. 2005). The first model indicated a significant MS $\times$ self-esteem interaction on the dependent variable (total number of cookies eaten; $\beta=0.19, t=$ $2.04, p<.05)$. The second model revealed a significant MS $\times$ self-esteem interaction on the mediator (number of first-person pronouns used; $\beta=-0.26, t=-2.84, p<$ $.01)$. The third model revealed that the effect of the MS $\times$ self-esteem interaction on the number of cookies eaten became nonsignificant $(\beta=0.03, t=0.32, p>.75)$, whereas the number of first-person pronouns had a significant effect on the number of cookies eaten $(\beta=-0.56, t=-6.51$, $p<.01)$. A Sobel (1982) test revealed that the decrease in the direct effect of the interaction effect of MS and selfesteem was statistically significant $(z=2.61, p<.01)$. Thus, the number of first-person pronouns used for translation is supported as a mediator of the effect of MS and self-esteem on the total number of cookies eaten.

\section{Discussion}

Experiment 3 replicated the mediational pattern found in experiment 2, using a different dependent variable and a different mediator. Instead of using the shopping list task, in which participants had to select products for consumption, we measured actual consumption of cookies. We measured escape from self-awareness by counting the number of firstperson pronouns that participants used to translate a foreign language and found that LSE individuals used fewer firstperson pronouns in the MS condition than in the pain condition, reflecting a state of escape from self-awareness. Further, this state affected their eating behavior. LSE individuals ate more in the MS condition than in the pain condition, and this effect of MS on cookie eating was mediated by the number of first-person pronouns used. In contrast, HSE consumers did not differ in their state of self-awareness and cookie eating between the MS and pain conditions. In experiment 4, we examine whether further heightening the level of self-awareness strengthens the effect of MS on consumption quantities for LSE consumers.

\section{EXPERIMENT 4}

In the previous two experiments, we examined to what extent escape from self-awareness mediated the effects of MS on consumption behavior. In experiment 4 , we attempt to find additional evidence for our proposed mechanism by manipulating the level of self-awareness. To test hypothesis 3 , we examine whether the manipulated level of self-awareness interacts with MS and self-esteem in determining the number of snacks and drinks participants choose from a shopping list.

In prior research, self-awareness has been manipulated by placing participants in front of a mirror (Duval and Wicklund 1972; Pryor et al. 1977). Following this paradigm, we used three self-awareness (SA) conditions. In the "SA-escape" condition, participants were exposed to a mirror while writing an essay about either death or pain. Then, during subsequent tasks (i.e., picking snacks and drinks for future consumption), participants were no longer exposed to the mirror. By removing the mirror, we allowed participants to escape from this heightened self-awareness state (Dixon and Baumeister 1991). In the "SA-no escape" condition, participants faced the mirror while both writing about death (or pain) and picking snacks and drinks. By constantly sitting in front of the mirror, participants did not have a chance to escape from self-awareness. Finally, in the "no-SA" condition, participants were not exposed to a mirror at all, similar to earlier experiments. We expected, in line with earlier experiments, 
that HSE consumers would not be affected by the level of self-awareness or by the MS manipulation. LSE consumers, however, should be strongly affected by both the MS manipulation and the manipulated level of self-awareness.

In both the SA-escape condition and the no-SA condition, we expected that LSE consumers would want to purchase more snacks and drinks when they wrote about death, compared to when they wrote about pain, due to a desire to escape from self-awareness. Furthermore, we expected a higher level of purchasing in the SA-escape condition compared to the no-SA condition, because the presence of a mirror heightens the level of self-awareness, making MS feel even more aversive (Arndt et al. 1998) and thus increasing the need to escape. However, in the SA-no escape condition, participants were constantly exposed to a mirror and thus were unable to escape from self-awareness. Based on classic self-awareness findings (Pryor et al. 1977; Scheier and Carver 1977), we expected that when participants were forced to remain in an aversive state of high self-awareness, they would have no choice but to attempt to live up to societal standards, perhaps even by reducing their food-consumption levels (Goldenberg et al. 2005).

\section{Method}

This experiment utilized a 3 (self-awareness: SA-escape vs. SA-no escape vs. no-SA) $\times 2$ (MS: death vs. pain) $\times$ 2 (self-esteem: low vs. high) between-subjects design. One hundred and fifty-one participants came to the lab in partial fulfillment of course requirements. Two participants did not complete the full experiment and were therefore omitted from later data analyses. Hence, 149 participants were included in the data set.

A week before the experiment took place, participants completed the Rosenberg self-esteem scale. Upon arrival in the lab, participants were placed in individual cubicles and told that they would participate in several unrelated studies. Participants in the SA-escape and SA-no escape conditions sat in a cubicle that was equipped with a mirror facing the participants. Participants in the no-SA condition sat in a cubicle that was not equipped with a mirror. While sitting in these cubicles, participants completed either the death essay or pain essay, as in prior experiments. Subsequently, they filled out the PANAS and several filler questions.

Participants were then told that the experimenter needed to use the computer in his or her cubicle and, therefore, they were asked to perform the next task in an adjacent cubicle. Participants in the SA-no escape condition moved to a cubicle that was also equipped with a mirror facing the participant. Participants in the SA-escape condition and no-SA condition moved to a cubicle that was not equipped with a mirror. Participants then chose hypothetical snacks and drinks from a shopping list, as in prior studies. They ended the experiment by completing a postexperimental questionnaire, which revealed that none of the participants indicated any suspicion about the manipulations or relatedness between the different tasks of the experiment.

\section{Results}

We performed a 3 (self-awareness: SA-escape vs. SA-no escape vs. no-SA) $\times 2$ (MS: death vs. pain) $\times 2$ (selfesteem: low vs. high) between-subjects ANOVA on the total number of items chosen. The ANOVA revealed a main effect of self-awareness $(F(2,137)=24.12, p<.001)$. Participants in the SA-escape condition chose more items $(M=25.16)$ than did participants in the no-SA condition $(M=22.90)$, who in turn chose more items than participants in the SA-no escape condition $(M=19.17)$. There was also a main effect of self-esteem $(F(1,137)=9.32$, $p<.01)$. LSE participants chose more items $(M=23.67)$ than did HSE participants $(M=21.58)$. We also obtained a significant three-way interaction among self-awareness, MS, and self-esteem $(F(2,137)=6.20, p<.01)$, supporting hypothesis 3 (see fig. 3).

As expected, MS did not influence the purchase quantities of HSE consumers in any of the three self-awareness conditions (values of $F<1$ and $p>.40$ ). In contrast, MS had a significant effect on the purchase quantities of LSE consumers in all three self-awareness conditions. LSE consumers who wrote about death purchased more items than LSE consumers who wrote about pain in the SA-escape condition $(M=30.93$ vs. $M=26.83 ; F(1,137)=7.32, p<.01)$ and the no-SA condition $(M=26.42$ vs. $M=21.54$; $F(1,137)=10.03, p<.01)$. However, LSE consumers who wrote about death purchased marginally fewer items than LSE consumers who wrote about pain in the SA-no escape condition $(M=16.17$ vs. $M=19.08 ; F(1,137)=3.45$, $p<.06$ ). Further post hoc analyses (Tukey HSD) revealed that LSE consumers who wrote about death purchased more items in the SA-escape condition than in the no-SA condition $(p<.05)$, in which they purchased more than in the SA-no escape condition $(p<.05)$. In addition, LSE consumers who wrote about pain purchased more items in the SA-escape condition than those in the no-SA condition and the SA-no escape conditions $(p<.05)$, with the latter two conditions not significantly different from each other.

\section{Discussion}

In this experiment, we manipulated the level of selfawareness and whether participants were able to escape from it and examined its moderating role on the effect of MS and self-esteem on purchase quantities. We replicated earlier findings in the no-SA condition: participants who wrote about death purchased higher quantities of snacks and drinks compared to participants who wrote about pain. In the SAescape condition, where participants were only exposed to the mirror during the essay task (but not during the shopping list task), we also found that participants who wrote about death purchased higher quantities of items than participants who wrote about pain. However, participants who wrote about either death or pain consumed more in the SA-escape condition than in the no-SA condition. Hence, comparing the no-SA condition and the SA-escape condition, we find additive effects of MS and self-awareness on the chosen 
FIGURE 3

EXPERIMENT 4 RESULTS: THE EFFECTS OF MORTALITY SALIENCE AND SELF-AWARENESS ON TOTAL ITEMS SELECTED FOR LOW- AND HIGH-SELF-ESTEEM CONSUMERS
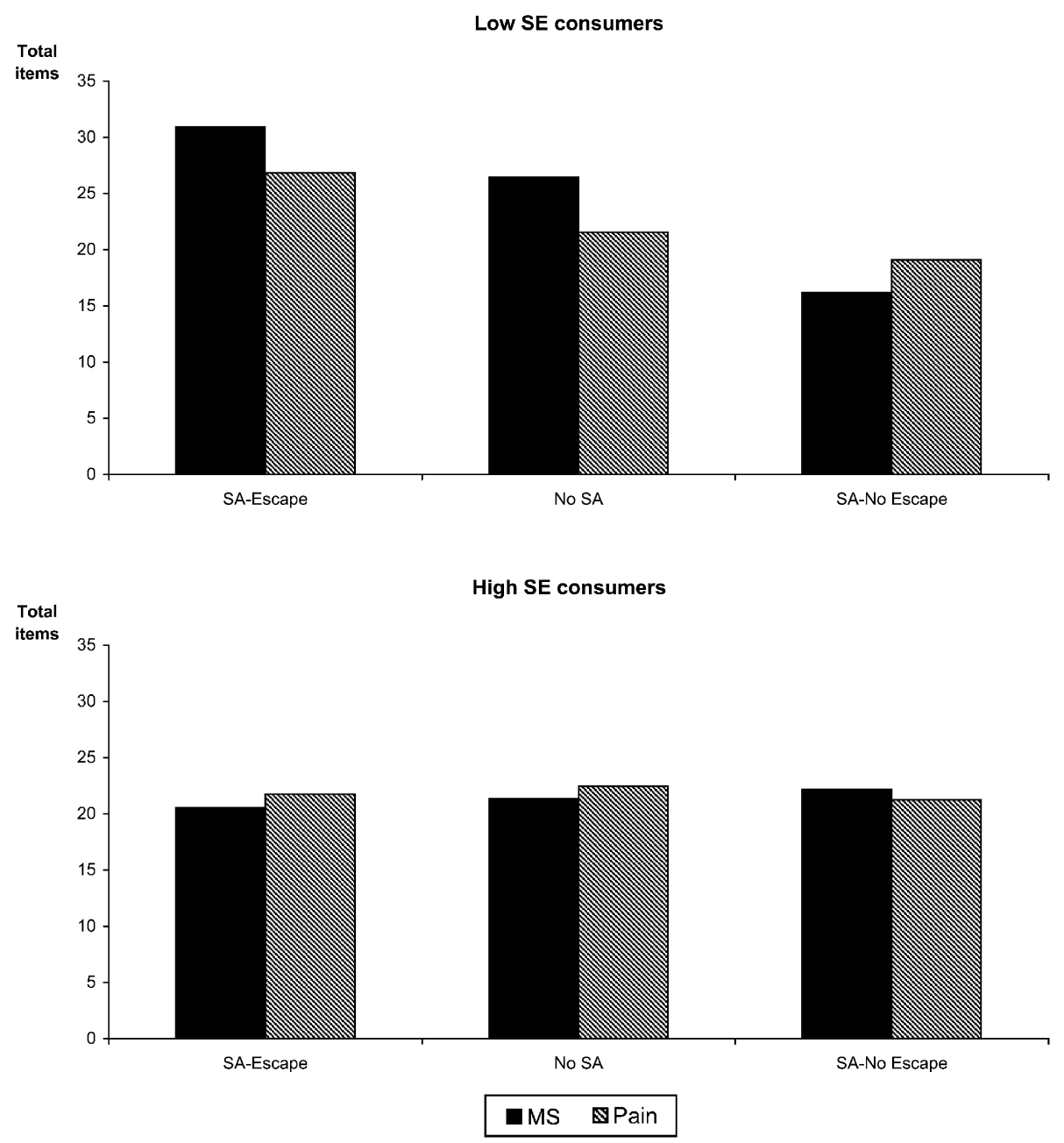

number of snacks and drinks. Both MS and the mirror are sources of increased self-awareness and, because participants are given the chance to escape from self-awareness, these sources lead separately (in the case of participants who write about death in the control self-awareness condition and participants who write about pain in the escape from self-awareness condition) to increased consumption. When both sources are combined (in the case of participants who write about their own death in the escape from self-awareness condition), participants purchase even more snacks and drinks.

In the SA-no escape condition, in which participants were constantly exposed to the mirror and not able to escape, those who wrote about death did not pursue higher quantities of snacks and drinks compared to participants who wrote about pain. In fact, participants who wrote about death actually purchased marginally fewer snacks and drinks than participants who wrote about pain. This finding is consistent with early self-awareness research (Pryor et al. 1977; Scheier and Carver 1977), in which individuals are unable to escape selfawareness and thus must attempt to change behavior in order to reduce ideal-actual self-discrepancies. This result is also in line with the research by Goldenberg et al. (2005), who found that MS can decrease consumption levels when upward social comparisons are made. When individuals remain in such uncomfortable situations during the consumption decision, they are likely to restrict consumption.

\section{GENERAL DISCUSSION}

The human animal is a beast that dies and if he's got money he buys and buys and buys and I think the reason he buys everything he can buy is that in the back of his mind he has the crazy hope that one of his purchases will be life everlasting! (Tennessee Williams, Cat on a Hot Tin Roof) 
The terrorist attacks on the World Trade Center in 2001, as well as world events such as hurricanes and tsunamis, have dramatically increased the salience of death-related thoughts for many individuals (Pyszczynski et al. 2003). While MS is not chronically accessible, it is frequently accessible among many individuals, and one way in which they may cope is through their consumption behavior. Reports following 9/11 suggested that consumers engaged themselves in excessive eating, as well as excessive spending, compared to before the attacks. For example, both Baskin-Robbins and Safeway supermarkets reported increased sales immediately following 9/11 (Hubler 2001).

Our results support this anecdotal evidence that increasing MS leads to more excessive consumption patterns. Thoughts of death lead to the potential for anxiety (Greenberg et al. 2003), and individuals, particularly those with low selfesteem, may try to prevent experiencing actual anxiety by engaging in actions that allow them to escape from selfawareness. Furthermore, we demonstrated that the effect of MS on the consumption behavior of LSE individuals was mediated by a desire to escape from self-awareness (measured by either choosing a chair to sit away from a mirror or the decreased use of first-person pronouns). This mediational evidence provides strong support for an escape-fromself-awareness explanation for our results. Finally, we demonstrated that increasing self-awareness even further by placing participants in front of a mirror strengthens the effects of MS on consumption. Hence, across four studies we demonstrated that MS leads to increased consumption for LSE consumers but not for HSE consumers. Only when LSE consumers do not have the opportunity to escape from a state of heightened self-awareness does MS lead to decreased consumption.

Researchers inspired by terror management theory have devoted much effort to uncovering the ways in which individuals deal with the threat of death. In addition to the two established MS defense strategies (defending the predominant cultural worldview and bolstering self-esteem), researchers have recently started to examine other defense strategies, such as nostalgia proneness (Routledge et al. 2008) or attachment-related defensive actions (Hart, Shaver, and Goldenberg 2005). Hart et al. (2005, 1011) suggest that "other provocative possibilities for defensive mechanisms may be found in basic and common activities such as eating (e.g., comfort food), shopping, sexual activity, and entertainment." In fact, our findings are completely in line with their plea for novel defensive mechanisms against the threat of death. In four studies, we support our proposition that MS may lead to an escape-from-self-awareness strategy for consumers with low self-esteem.

Our findings contribute to the literature in several ways. We are the first to show that MS can lead consumers to engage in higher levels of overall consumption, in terms of both planning purchases of food and drinks and actual eating behavior. Furthermore, we contribute to the psychology literature by establishing a mechanism (escape from selfawareness) by which consumers overconsume in an attempt to cope with the fear of death. We also add to a growing body of literature that addresses the subtle, nonconscious effects of the activation of self-related goal pursuits on human behavior (Bargh 2002).

Our research differs significantly from that of Ferraro et al. (2005), who demonstrated that MS leads consumers to make a specific choice among two product alternatives (fruit salad vs. chocolate cake). These authors were more interested in how female consumers' body esteem played a role in the choice for a specific product in the face of MS. In contrast, we were not interested in the specific dietary choice among a set of alternatives but rather in how MS can affect the total amount of consumption. This research also significantly differs from the work of Kasser and Sheldon (2000), who suggested that MS leads individuals to demonstrate more materialistic values. Participants in their studies predicted higher salaries for themselves in the future and took more allocations from a resource dilemma. However, Kasser and Sheldon (2000) did not use a standard materialism scale (Richins and Dawson 1992), but rather a scale about personal strivings, and measured materialism as a high rating on the strivings for an attractive appearance, social recognition, and financial success. In contrast, our research examines the effect of MS on the desire for everyday consumable products rather than luxury brands such as Lexus or Rolex that might demonstrate one's financial status (Mandel and Heine 1999). Our findings suggest that MS participants in Kasser and Sheldon's (2000) and Mandel and Heine's (1999) research may have desired a higher salary and/or luxury brands in order to increase overall consumption and spending rather than as a means to display status or wealth. Furthermore, in experiment 3 we demonstrate MS effects on actual eating behavior, in contrast to the hypothetical choices made by participants in the prior research cited above.

There are also several limitations to our current research. First, our participants were limited to American and European undergraduate business students. It would be worthwhile to study other individual differences. For instance, would the effects be stronger for older individuals, who are closer to death, due to an even shorter, more compressed time horizon? Moreover, our results might not apply as strongly to cultures in which excessive consumption is not valued as highly. In addition, it is unclear from our results whether the escape-from-self-awareness strategy relies mainly on overconsumption of food and drinks or overspending in general. In particular, the consumption of glucose-laden products seems to aid individuals in acts of selfcontrol, including suppression of thoughts about death (Gailliot et al. 2007). Future research might explore whether an increased consumption quantity of nonfood consumables (such as music downloads) can also help LSE individuals to escape from self-awareness.

One alternative account for our findings is a survival or self-preservation explanation. Humans have evolved to hoard excess calories as a means for survival during a famine (Burnham and Phelan 2000). Therefore, MS may lead to 
increased food consumption not as a way to escape selfawareness but rather because it triggers a survival instinct, which may cause people to consume more calories. However, our particular pattern of results does not support this explanation. A survival mechanism should occur equally for LSE and HSE consumers, or perhaps be even stronger for HSE consumers, who may feel they have more to lose. In contrast, we found a stronger effect for LSE consumers than for HSE consumers. This particular pattern of results is also inconsistent with a self-regulatory explanation. Gailliot et al. (2006) demonstrated that MS participants performed worse on tasks that require self-regulation, such as resolving anagrams or analytical reasoning problems, compared to control participants. However, their effects were not moderated by self-esteem, contrary to the majority of findings in the MS literature (Pyszczynski et al. 2004). In support of their findings, Gailliot et al. (2006) argued that selfregulatory effects of MS occur independently of self-esteem. In contrast, our studies consistently demonstrated MS effects that were moderated by self-esteem. Therefore, self-regulation does not appear to provide the best explanation for our findings.

An interesting question is why participants needed to take two separate actions in order to escape from self-awareness: both choosing to sit away from the mirror and purchasing more snacks (experiment 2), and both using fewer pronouns in the translation task and eating more cookies (experiment 3 ). The pronoun-usage and mirror tasks are well-established measures of a desire to escape from self-awareness (Twenge et al. 2003), but they do not necessarily accomplish the task. The quantity of consumption reflects the actual attempt to escape self-awareness, and prior evidence suggests that it is often effective (Heatherton and Baumeister 1991). However, the fact that LSE participants want to escape from selfawareness does not mean that they can simply turn off selfawareness. Escaping basically means that self-awareness is turned to a very low level. This often happens through a state of cognitive deconstruction (Baumeister 1990), which can evoke several specific mind-sets such as constricted temporal focus, concrete thinking, focusing on immediate goals, or cognitive rigidity. Future research may provide more insights into the process by which LSE consumers engage in cognitive deconstruction as a means to escape from selfawareness, as well as the change in self-awareness levels after various attempts to escape.

Our results suggest several additional avenues for future research. For example, it might be interesting to investigate whether MS effects on product consumption are brandspecific. MS activates nationalistic concepts in people (Arndt, Greenberg, and Cook 2002). Therefore, MS may induce consumer ethnocentrism, causing consumers to develop more positive attitudes toward (and thus higher consumption of) domestic brands versus nondomestic brands (Maheswaran and Agrawal 2004). Another possibility for future research would be to investigate whether MS affects the timing of consumption. MS might cause individuals to adopt a limited time horizon, thereby placing more value on immediate consumption relative to delayed consumption. Because they believe that they might die soon, MS individuals might prefer to spend their money on items that can be consumed immediately, rather than save their money, which will be useless to them upon their deaths.

Our findings may also have practical implications. Consumers, especially those with a lower self-esteem, might be more susceptible to overconsumption when confronted with images of death during the news or their favorite crime scene investigation shows. Another interesting question is whether putting a mirror (or a picture of oneself) on the refrigerator can help curb overeating. Our results suggest that such a strategy would work only if the mirror (or picture) remains visible during the act of consumption. One possible avenue for future research is identifying healthier strategies, rather than overconsuming, in which consumers can deal with existential threats.

\section{REFERENCES}

Arndt, Jamie, Jeff Greenberg, and Alison Cook (2002), "Mortality Salience and the Spreading Activation of Worldview-Relevant Constructs: Exploring the Cognitive Architecture of Terror Management," Journal of Experimental Psychology: General, 131 (September), 307-24.

Arndt, Jamie, Jeff Greenberg, Linda Simon, Tom Pyszczynski, and Sheldon Solomon (1998), "Terror Management and SelfAwareness: Evidence That Mortality Salience Provokes Avoidance of the Self-Focused State," Personality and Social Psychology Bulletin, 24 (November), 1216-27.

Arndt, Jamie, Jeff Schimel, and Jamie L. Goldenberg (2003), "Death Can Be Good for Your Health: Fitness Intentions as a Proximal and Distal Defense against Mortality Salience," Journal of Applied Social Psychology, 33 (August), 1726-46.

Arndt, Jamie, Sheldon Solomon, Tim Kasser, and Kennon M. Sheldon (2004), "The Urge to Splurge: A Terror Management Account of Materialism and Consumer Behavior," Journal of Consumer Psychology, 14 (3), 198-212.

Bargh, John A. (2002), "Losing Consciousness: Automatic Influences on Consumer Judgment, Behavior, and Motivation," Journal of Consumer Research, 29 (September), 280-85.

Baumeister, Roy F. (1990), "Suicide as Escape from Self," Psychological Review, 97 (1), 90-113.

Baumeister, Roy F., Todd F. Heatherton, and Dianne M. Tice (1993), "When Ego Threats Lead to Self-Regulation Failure: Negative Consequences of High Self-Esteem," Journal of Personality and Social Psychology, 64 (January), 141-56.

Becker, Ernest (1973), The Denial of Death, New York: Free Press. Burnham, Terry and Jay Phelan (2000), Mean Genes: From Sex to Money to Food: Taming Our Primal Instincts, New York: Penguin.

Chandon, Pierre and Brian Wansink (2006), "How Biased Household Inventory Estimates Distort Shopping and Storage Decisions," Journal of Marketing, 70 (October), 118-35.

Cosgrove, Julia (2001), "What-the-Hell Consumption," Business Week, October 29, 12.

Crocker, Jennifer and Lora E. Park (2004), "The Costly Pursuit of Self-Esteem," Psychological Bulletin, 130 (May), 392-414.

Davis, Deborah and Timothy C. Brock (1978), "Use of First-Person Pronouns as a Function of Increased Objective Self-Aware- 
ness and Performance Feedback," Journal of Experimental Social Psychology, 11 (July), 381-88.

Dixon, Thomas M. and Roy F. Baumeister (1991), "Escaping the Self: The Moderating Effect of Self-Complexity," Personality and Social Psychology Bulletin, 17 (August), 363-68.

Duval, T. Shelley and Robert A. Wicklund (1972), A Theory of Objective Self-Awareness, New York: Academic Press.

Faber, Ronald J. and Thomas C. O'Guinn (1992), "A Clinical Screener for Compulsive Buying," Journal of Consumer Research, 19 (December), 459-69.

Ferraro, Rosellina, Baba Shiv, and James R. Bettman (2005), "Let Us Eat and Drink, for Tomorrow We Shall Die: Effects of Mortality Salience and Self-Esteem on Self-Regulation in Consumer Choice," Journal of Consumer Research, 32 (June), 65-75.

French, Simone A., Mary Story, and Cheryl L. Perry (1995), "SelfEsteem and Obesity in Children and Adolescents: A Literature Review," Obesity Research, 3, 479-90.

Gailliot, Matthew T., C. Nathan DeWall, Roy F. Baumeister, Jon K. Maner, and E. Ashby Plant (2007), "Self-Control Relies on Glucose as a Limited Energy Source: Willpower Is More than a Metaphor," Journal of Personality and Social Psychology, 92 (February), 325-36.

Gailliot, Matthew T., Brandon J. Schmeichel, and Roy F. Baumeister (2006), "Self-Regulatory Processes Defend against the Threat of Death: Effects of Self-Control Depletion and Trait Self-Control on Thoughts and Fears of Dying," Journal of Personality and Social Psychology, 91 (1), 49-62.

Goldenberg, Jamie L., Jamie Arndt, Joshua Hart, and Megan Brown (2005), "Dying to Be Thin: The Effects of Mortality Salience and Body Mass Index on Restricted Eating among Women," Personality and Social Psychology Bulletin, 31 (October), $1400-1412$.

Greenberg, Jeff, Andy Martens, Eva Jonas, Donna Eisenstadt, Tom Pyszczynski, and Sheldon Solomon (2003), "Psychological Defense in Anticipation of Anxiety: Eliminating the Potential for Anxiety Eliminates the Effect of Mortality Salience on Worldview Defense," Psychological Science, 14 (September), 516-19.

Greenberg, Jeff and Catherine Musham (1981), "Avoiding and Seeking Self-Focused Attention," Journal of Research in Personality, 15, 191-200.

Greenberg, Jeff, Tom Pyszczynski, and Sheldon Solomon (1986), "The Causes and Consequences of the Need for Self-Esteem: A Terror Management Theory," in Public and Private Self, ed. R. F. Baumeister, New York: Springer, 189-212.

Greenberg, Jeff, Tom Pyszczynski, Sheldon Solomon, Abram Rosenblatt, Mitchell Veeder, Shari Kirkland, and Deborah Lyon (1990), "Evidence for Terror Management II: The Effect of Mortality Salience on Reactions to Those Who Threaten or Bolster the Cultural Worldview," Journal of Personality and Social Psychology, 58 (February), 303-18.

Greenberg, Jeff, Tom Pyszczynski, Sheldon Solomon, Linda Simon, and Michael Breus (1994), "Role of Consciousness and Accessibility of Death-Related Thoughts in Mortality Salience Effects," Journal of Personality and Social Psychology, 67 (October), 627-37.

Greenberg, Jeff, Sheldon Solomon, and Tom Pyszczynski (1997), "Terror Management Theory of Self-Esteem and Cultural Worldviews: Empirical Assessments and Conceptual Refinements," in Advances in Experimental Social Psychology, Vol. 29, ed. Mark P. Zanna, San Diego, CA: Academic Press, 61-139.
Hanley, Alice and Mari S. Wilhelm (1992), "Compulsive Buying: An Exploration into Self-Esteem and Money Attitudes," Journal of Economic Psychology, 13, 5-18.

Harmon-Jones, Eddie, Linda Simon, Jeff Greenberg, Tom Pyszczynski, Sheldon Solomon, and Holly McGregor (1997), "Terror Management Theory and Self-Esteem: Evidence That Increased Self-Esteem Reduces Mortality Salience Effects," Journal of Personality and Social Psychology, 72 (January), 24-36.

Hart, Joshua J., Philip R. Shaver, and Jamie L. Goldenberg (2005), "Attachment, Self-Esteem, Worldviews, and Terror Management: Evidence for a Tripartite Security System," Journal of Personality and Social Psychology, 88 (June), 999-1013.

Heatherton, Todd F. and Roy F. Baumeister (1991), "Binge Eating as Escape from Self-Awareness," Psychological Bulletin, 110 (January), 86-108.

Heatherton, Todd F., C. Peter Herman, and Janet Polivy (1992), "Effects of Physical Threat and Ego Threat on Eating Behavior," Journal of Personality and Social Psychology, 62 (May), 798-800.

Hubler, Shawn (2001), "Americans Fend Off Sorrow with Laden Fork and Spoon; People Are Craving Sweets, Getting Together for Potlucks, Canning Goods, Baking Pies, and Carbo Loading (and Therefore Exercising)," Los Angeles Times, October 2, E1.

Kahn, Barbara E. and Alice M. Isen (1993), "The Influence of Positive Affect on Variety Seeking among Safe, Enjoyable Products," Journal of Consumer Research, 20 (September), 257-70.

Kasser, Tim and Kennon M. Sheldon (2000), "Of Wealth and Death: Materialism, Mortality Salience, and Consumption Behavior," Psychological Science, 11 (July), 348-51.

Landau, Mark J. and Jeff Greenberg (2006), "Play It Safe or Go for the Gold? A Terror Management Perspective on SelfEnhancement and Self-Protective Motives in Risky Decision Making," Personality and Social Psychology Bulletin, 32 (December), 1633-45.

Maheswaran, Durairaj and Nidhi Agrawal (2004), "Motivational and Cultural Variations in Mortality Salience Effects: Contemplations on Terror Management Theory and Consumer Behavior," Journal of Consumer Psychology, 14 (3), 213-18.

Mandel, Naomi and Steven J. Heine (1999), "Terror Management and Marketing: He Who Dies with the Most Toys Wins," Advances in Consumer Research, 26, 527-32.

Mills, Jennifer S., Janet Polivy, C. Peter Herman, and Marika Tiggemann (2002), "Effects of Exposure to Thin Media Images: Evidence of Self-Enhancement among Restrained Eaters," Personality and Social Psychology Bulletin, 28 (December), 1687-99.

Moskalenko, Sophia and Steven J. Heine (2003), "Watching Your Troubles Away: Television Viewing as a Stimulus for Subjective Self-Awareness," Personality and Social Psychology Bulletin, 29 (January), 76-85.

Muller, Dominique, Charles M. Judd, and Vincent Y. Yzerbyt (2005), "When Moderation Is Mediated and Mediation Is Moderated," Journal of Personality and Social Psychology, 89 (December), 852-63.

Polivy, Janet, C. Peter Herman, and Traci McFarlane (1994), "Effects of Anxiety on Eating: Does Palatability Moderate Distress-Induced Overeating in Dieters?" Journal of Abnormal Psychology, 103 (3), 505-10.

Pryor, John B., Frederick X. Gibbons, Robert A. Wicklund, Russell H. Fazio, and Ronald Hood (1977), "Self-Focused Attention 
and Self-Report Validity," Journal of Personality, 45 (December), 513-27.

Pyszczynski, Tom, Jeff Greenberg, Sheldon Solomon, Jamie Arndt, and Jeff Schimel (2004), "Why Do People Need Self-Esteem? A Theoretical and Empirical Review," Psychological Bulletin, 130 (May), 435-68.

Pyszczynski, Tom, Sheldon Solomon, and Jeff Greenberg (2003), In the Wake of 9/11: The Psychology of Terror, Washington, DC: American Psychological Association.

Richins, Marsha L. and Scott Dawson (1992), "A Consumer Values Orientation for Materialism and Its Measurement: Scale Development and Validation," Journal of Consumer Research, 19 (December), 303-16.

Rosenberg, Morris (1989), Society and the Adolescent Self-Image, rev. ed., Middletown, CT: Wesleyan University Press.

Rosenblatt, Abram, Jeff Greenberg, Sheldon Solomon, Tom Pyszczynski, and Deborah Lyon (1989), "Evidence for Terror Management Theory I: The Effects of Mortality Salience on Reactions to Those Who Violate or Uphold Cultural Values," Journal of Personality and Social Psychology, 57 (October), 681-90.

Routledge, Clay, Jamie Arndt, Constantine Sedikides, and Tim Wildschut (2008), "A Blast from the Past: The Terror Management Function of Nostalgia," Journal of Experimental Social Psychology, 44 (January), 132-40.

Scheier, Michael F. and Charles S. Carver (1977), "Self-Focused Attention and the Experience of Emotion: Attraction, Repulsion, Elation, and Depression," Journal of Personality and Social Psychology, 35 (September), 625-36.

Scheier, Michael F., Allan Fenigstein, and Arnold H. Buss (1974), "Self-Awareness and Physical Aggression," Journal of Experimental Social Psychology, 10 (May), 264-73.

Schmeichel, Brandon J. and Andy Martens (2005), "Self-Affirmation and Mortality Salience: Affirming Values Reduces
Worldview Defense and Death-Thought Accessibility," Personality and Social Psychology Bulletin, 31 (May), 658-67.

Silvia, Paul J. (2001), "Nothing or the Opposite: Intersecting Terror Management and Objective Self-Awareness," European Journal of Personality, 15, 73-82.

Sobel, Michael E. (1982), "Asymptotic Confidence Intervals for Indirect Effects in Structural Equations Models," in Sociological Methodology, ed. Samuel Leinhart, San Francisco: Jossey-Bass, 290-312.

Solomon, Sheldon, Jeff Greenberg, and Tom Pyszczynski (1991), "A Terror Management Theory of Social Behavior: The Psychological Functions of Self-Esteem and Cultural Worldviews," in Advances in Experimental Social Psychology, Vol. 24, ed. Mark E. P. Zanna, San Diego, CA: Academic Press, 93-159.

Spencer, Jane and Cynthia Crossen (2003), "Why Do Americans Believe Danger Lurks Everywhere?" Wall Street Journal, April 24, 1.

Twenge, Jean M., Kathleen R. Catanese, and Roy F. Baumeister (2003), "Social Exclusion and the Deconstructed State: Time Perception, Meaninglessness, Lethargy, Lack of Emotion, and Self Awareness," Journal of Personality and Social Psychology, 85 (September), 409-23.

Vohs, Kathleen D. and Ronald J. Faber (2007), "Spent Resources: Self-Regulatory Resource Availability Affects Impulse Buying," Journal of Consumer Research, 33 (March), 537-47.

Watson, David, Lee A. Clark, and Auke Tellegen (1988), "Development and Validation of Brief Measures of Positive and Negative Affect: The PANAS Scales," Journal of Personality and Social Psychology, 53 (June), 1063-70.

White, Gregory L. and Shirley Leung (2002), "American Tastes Move Upscale, Forcing Manufacturers to Adjust," Wall Street Journal, March 29. 